\title{
Very rare upperdorsal intramedullary epidermoid with paraplegia: a case report
}

\author{
Md. Atikur Rahman', Bipin Kumar Chaurasia', Md. Arif Hossain'1, Saequa Habib², Kanak Kanti Barua ${ }^{1}$ \\ 'Department of Neurosurgery, Bangabandhu Sheikh Mujib Medical University, Dhaka 1000, Bangladesh. \\ 2Department of Pathology, Bangabandhu Sheikh Mujib Medical University, Dhaka 1000, Bangladesh. \\ Correspondence to: Dr. Md. Atikur Rahman, Department of Neurosurgery, Bangabandhu Sheikh Mujib Medical University, Dhaka \\ 1000, Bangladesh. E-mail: atiquessmc@gmail.com; Dr. Bipin Kumar Chaurasia, Department of Neurosurgery, Bangabandhu Sheikh \\ Mujib Medical University, Dhaka 1000,Bangladesh. E-mail: trozexa@gmail.com
}

\begin{abstract}
How to cite this article: Rahman MA, Chaurasia BK, Hossain MA, Habib S, Barua KK. Very rare upperdorsal intramedullary epidermoid with paraplegia: a case report. Neuroimmuno/ Neuroinflammation 2018;5:14.

http://dx.doi.org/10.20517/2347-8659.2017.57
\end{abstract}

Received: 14 Nov 2017 Frist Decision: 26 Feb 2018 Revised: 15 Mar 2018 Accepted: 15 Mar 2018 Published: 23 Apr 2018

Science Editor: Athanassios P. Kyritsis Copy Editor: Jun-Yao Li Production Editor: Huan-Liang Wu

\begin{abstract}
Intramedullary upperdorsal epidermoid tumor is very rare. As far as we know, a small number of epidermoid tumors in the spinal cord have been reported in the journal for a long time. Most of the time, the spinal cord epidermoids are intradural extramedullary. We are reporting a case of a 21-year-old young man with paraplegia and upper dorsal pain for 6 months with normal physical findings. Magnetic resonance imaging scan shows that spinal intramedullary space occupying lesions in the dorsal 2/3 (D2/3) level. Total clearance was accomplished by performing laminectomy. Day to day paraplegia was improved. Histopathology was confirmed as an epidermoid tumor from two different centers.
\end{abstract}

Keywords: Upperdorsal, epidermoid, intramedullary

\section{INTRODUCTION}

Epidermoids are rare before late childhood and have slight female predominance. Cervical and upper thoracic epidermoids are rare and conus is the most common site. Epidermoid tumors are usually located intradural extra medullary, but conus/cauda equina may have intramedullary component (completely intramedullary lesions are rare $)^{[1]}$. An epidermoid cyst is a slow growing indolent rare lesion ${ }^{[2]}$. This tumor involving the spinal cord is quite uncommon. The opinion of the majority of authors is that these tumors arise from displaced normally developing somatic cells ${ }^{[3]}$. The vast majority of intraspinal epidermoid tumors are intradural and extramedullary. They are commonly associated with a dermal sinus and occur usually in the lumbosacral segments. In 1962, Manno et al ${ }^{[4]}$ in a review of all reported cases, found only

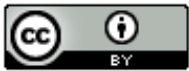

(C) The Author(s) 2018. Open Access This article is licensed under a Creative Commons Attribution 4.0 International License (https://creativecommons.org/licenses/by/4.0/), which permits unrestricted use, sharing, adaptation, distribution and reproduction in any medium or format, for any purpose, even commercially, as long as you give appropriate credit to the original author(s) and the source, provide a link to the Creative Commons license, and indicate if changes were made.

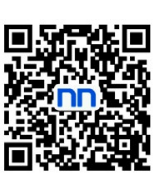


5 tumors that they classified as being intramedullary. The incidence of intraspinal epidermoid cysts in children is $3 \%$ and in adults is $1 \%{ }^{[1]}$. True intramedullary epidermoid cysts are rare, with $<60$ cases having been reported in the literature since the 1st reporting of the entity by Chiari in 1833. Of these, a very few have detailed radiographic evaluation. Intramedullary epidermoid cysts are common in the dorsal and lumbosacral region. Regions with two frequent localizations are T4-T6 and T11-T12, while only three cases have been reported with cervical cord involvement ${ }^{[5-7]}$. However, our case showed that there is epidermoid in the dorsal 2/3 level, which is very uncommon site and no association with dermal sinus.

\section{CASE REPORT}

A 21-year-old male was suffering from weakness of both lower limbs for 6 months, difficulty in walking for same duration, diminished sensation below mid chest for same duration along with constipation for 5 months and bladder disturbance for 1 month with erectile dysfunction. Weakness of both lower limbs which was insidious in onset, gradually progressive in nature, more on left side in comparison to right side of body below mid chest. His weakness was so severe nowadays that he encountered difficulties in walking and it was difficult to lift his body from kneeling position. Sometimes shoes run out of his feet. He complained about the numbness in his mid chest and diminished sensation of all modalities below mid chest and also complained of occasional incontinence of urine for last 1 month. He also complained of pain in back of mid chest for 3 months which was dull aching, mild in severity. There was no history of rest pain or night pain, and no definite aggravating or relieving factor. He didn't give any history of trau ma to back or any part of body, and there was no scar mark over back fever, cough or hemoptysis. Clinical examination showed upper limb normal and muscle power of lower limbs Medical Research Council grade 3, all jerks exaggerated and planter extensor with ankle and pateller clonus were present. Sensory level dorsal 4 and coordinations and gate could not be assessed. Regarding spine examinations revealed normal. Magnetic resonance imaging (MRI) of dorsal spine showed intramedullary cyst like space occupying lesions at the level of D2/3 which was contrast uptake only margin of the lesions [Figure 1]. MR myelogram revealed that it completely cut off the sign of cerebrospinal fluid (CSF) flow [Figure 1]. Operation is performed by laminectomy and complete removal of tumor. Intraoperative tumor exhibited a typical pearly white appearance, such as other epidermis-like tissues, which were removed by piece meal approach. Only the capsule that is firmly attached to the capsule can be removed. After proper homeostasis dura closed and skin also closed in layers. Postoperatively, muscle power was decrease and subsequent follow-up gradually improved along with autonomic functions. Now he can walk without support but better with aid. Confirmation of histopathology as epidermoid carcinoma from two deferent centers [Figure 2].

\section{DISCUSSION}

Epidermoid cysts (sebaceous cysts) are benign congenital lesions of ectodermal origin. Intracerebral epidermoid cysts are rare and may account for approximately $1.5 \%$ of all intracranial epidermoids and approximately $1 \%$ of all intra-cranial tumors. Epidermoids usually present around 20 to 40 years of age and occur in both men and women with the same frequency. They can be congenital or acquired. They can be both intradural and extradural ${ }^{[s]}$. Epidermoids are in good condition, smooth, lobulated, cystic lesions. Histologically, their inner layer is composed of stratified squamous epithelium with a layer of capsule. They tend to slowly enlarge as epithelial cells desquamate, foming keratin and cholesterol crystals in the center of the lesion. Handa et al. ${ }^{[9]}$ analyzed the aspirates of epidermal inclusion body of the epidermis to determine the cytological characteristics. Epidermoid cysts often occur in older age groups and show slower natural progression than most craniopharyngiomas. The epidermoid cyst wall consists of multiple layers of keratinized squamous epithelium which is located in the outer layer of collagen. The contents are more likely to be solid, keratinous, rather than the typical craniopharyngiomas oily fluid. The center of larger cysts sometimes degenerates, the keratin flakes are replaced with greasy brownish fluid that contain cholesterol crystals ${ }^{[10]}$. However, the reported case was a 21 -year-old boy, which may be a congenital cause of no history of trauma or previous surgery. Pathogenesis of spinal epidermoid is either congenital or acquired. 


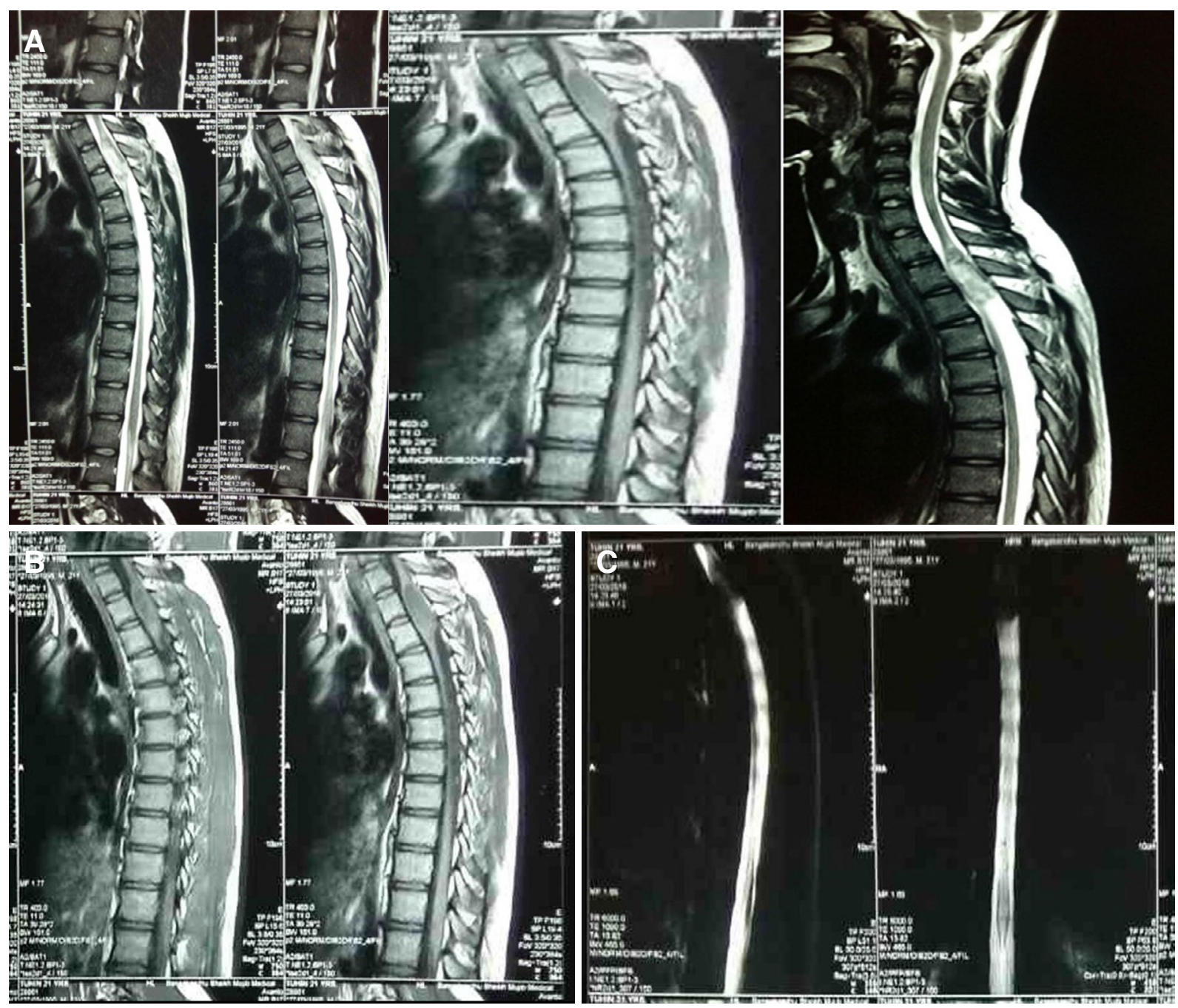

Figure 1. MRI of dorsal spine $T 1, T 2$, contrast films and MR myelogram. (A) MRI of dorsal spine $T 1$ and $T 2$ weighted images shows space occupying lesions at D2/3; (B) MRI of dorsal spine with contrast shows contrast uptake only periphery of the lesions; (C) MR myelogram shows gross obstruction of CSF flow. MRI: magnetic resonance imaging; CSF: cerebrospinal fluid
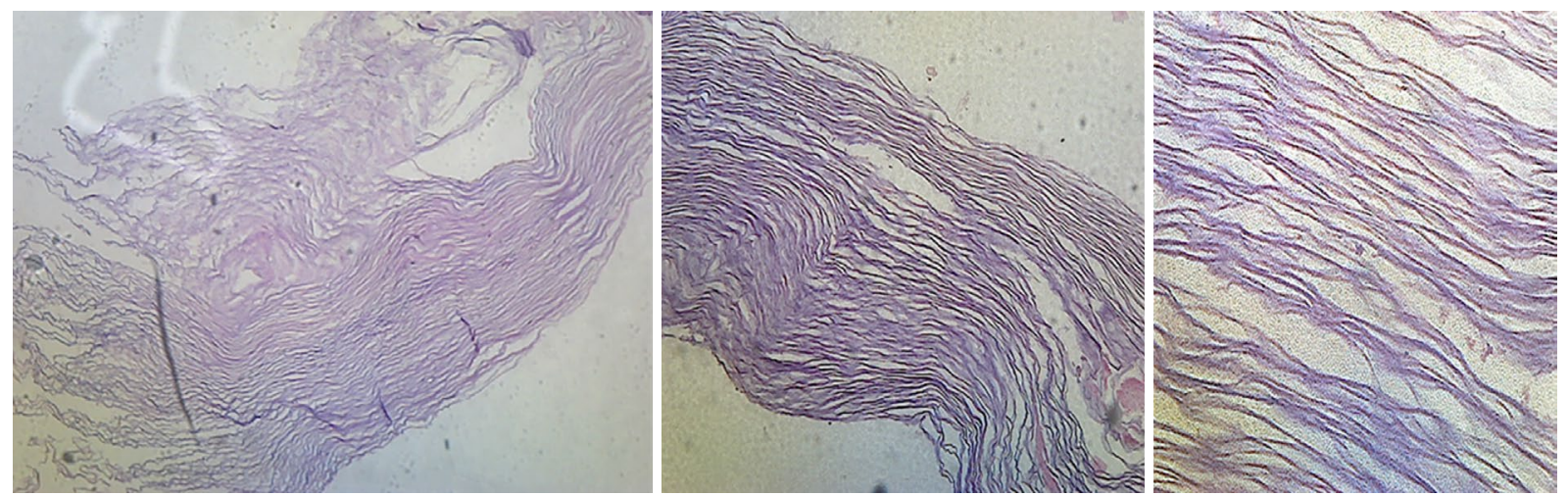

Figure 2. Photomicrograph of intramedullary epidermoid showing lamellated keratin (hematoxylin and eosin stain: $\times 4, \times 10, \times 40$ )

Due to the shift of ectodermal contents during neural tube closure, most of spinal epidermoid are congenital. Congenital epidermoid cyst can be associated with other abnormalities, e.g. hemivertebra, dermal sinus, spina bifida, syringomyelia, but they can also occur independently. It is reported that about 
$10 \%$ of the overlying bone defect is possible, but less frequent than in dermoid or some extramedullary epidermoids ${ }^{[2,4,11,12]}$. Dermoid and epidermoid tumors are usually intradural extramedullary (60\%) or intramedullary (40\%). The lower thoracic and lumbar regions are the most common locations. Conventional radiographs are generally normal but may demonstrate benign spinal canal widening with flattening of the pedicles and laminae. On computed tomography these tumors are usually seen as well demarcated masses are similar to the attenuation of CSF. The presence of calcification is more suggestive of a dermoid than an epidermoid tumor. Again, there may be focal osseous erosion or spinal canal widening. On MRI, dermoids are typically hypointense to hyperintense on T1 with variable signal intensities that reflect fat (hyperintense on T1) or calcium (decreased signal intensity on T1). Epidermoids on T1 are usually equal signal. Both tumors showed increased signal intensity on T2-weighted images. Typically, these tumors do not enhance after contrast administration and may demonstrate restricted diffusion ${ }^{[13]}$. In our case, MRI showed mixed intensity on T2 film and isointense on T1 film with contrast enhancement within the margin of the lesions [Figure 1]. Before operation it was confused regarding actual diagnosis of this lesion but per operative appearance and histopathology was confirmed the diagnosis of upper dorsal (D2/3) intramedullary epidermoid.

In conclusion, upper dorsal inamedullary epidermoids are simply rare lesions in neurosurgical practice. Only a few literatures showed spinal intramedullary epidermoid in different areas rather than upper dorsal. We report this case as a rare entity and found intramedullary epidermoid at the abnormal locations.

\section{DECLARATIONS}

\section{Authors' contributions}

Conception, diagnosis, design, and manuscript editing: Rahman MA

Manuscript preparation: Hossain MA

Histological diagnosis: Habib S

Technical and manuscript revision: Barua KK

Literature search: Chaurasia BK

\section{Financial support and sponsorship}

None.

\section{Conflicts of interest}

There are no conflicts of interest.

\section{Patient consent}

It was obtained from the patient.

\section{Ethics approval}

Not applicable.

\section{Copyright}

(c) The Author(s) 2018.

\section{REFERENCES}

1. Greenberg MS. Cyst and tumor like lesions. In: Handbook of Neurosurgery 8th Edition. New York: Thieme Publishers; 2016. p. 760.

2. Penisson-Besnier I, Guy G, Gandon Y. Intramedullary epidermoid cyst evaluated by computed tomographic scan and magnetic resonance imaging: case report. Neurosurgery 1989;25:955-9.

3. Craig RL. A case of epidermoid tumor of the spinal cord. Review of literature of spinal epidermoids and dermoids. Surgery 1943;13:354-67.

4. Manno NJ, Uihle A, Kernohan JW. Intraspinal epidermoids. J Neurosurg 1962;19:754-65.

5. Chandra PS, Manjari T, Devi BI, Chandramouli BA, Srikanth SG, Shankar SK. Intramedullary spinal epidermoid cyst. Neurol India 
2000;48:75-7.

6. Gonzalvo A, Hall N, McMahon JH, Fabinyi GC. Intramedullary spinal epidermoid cyst of the upper thoracic region. $J$ Clin Neurosci 2009;16:142-4.

7. Ogden AT, Khandji AG, McCormick PC, Kaiser MG. Intramedullary inclusion cysts of the cervicothoracic junction. Report of two cases in adults and review of the literature. $J$ Neurosurg Spine 2007;7:236-42.

8. Jimenez DF, Savage JG, Samuelson M. Developmental Anomalies: Arachnoid Cysts, Dermoid and Epidermoid. In: Ellenbogen RG, Abdulrauf SI, Sekhar LN, editors. Principles of Neurological Surgery, 3rd edition. Philadelphia: Elsevier Saunders; 2012. p. 134.

9. Handa U, Chabra S, Mohan H. Epidermal inclusion cyst: cytomorphological features and differential diagnosis. Diagn Cytopathol 2008;36:861-3.

10. Steno J. Craniopharyngiomas and Suprasellar Tumors. In: Ellenbogen RG, Abdulrauf SI, Sekhar LN, editors. Principles of Neurological Surgery, 3rd edition. Philadelphia: Elsevier Saunders; 2012. p. 612-3.

11. Gupta S, Gupta RK, Gujral RB, Mittal P, Kuriyal M, Krishnani N. Signal intensity patterns in intraspinal dermoids and epidermoids on MR imaging. Clin Radiol 1993;48:405-13.

12. Kirsch WM, Hodges FJ 3rd. An intramedullary epidermal inclusion cyst of the thoracic cord associated with a previously repaired meningocele. Case report. J Neurosurg 1966;24:1018-20.

13. Krishnaney A, Modic MT. Radiology of the Spine. In: Winn HR, editor. Youmans Neurological Surgery. 7th ed. Philadelphia: Elsevier; 2011.p. 335 